\title{
One-dimensional Fully Coupled Heat and Moisture Transfer Study using the Finite Volume Method
}

\author{
Lam Dang, Wey H. Leong Alan S. Fung \\ Department of Mechanical and Industrial Engineering \\ Ryerson University \\ Toronto, Ontario \\ lam.dang@ryerson.ca, weyleong@ryerson.ca, alanfung@ryerson.ca
}

\begin{abstract}
In this paper, one-dimensional coupled heat and mass transfer is studied using the finite volume method. The simulated results are compared with the experimental results and show good agreements with the experimental data. Soil from Northern Victoria County (silt loam, a medium soil) is compacted in a cylinder with 5 heat pulse probes to measure the thermal and moisture responses. Moisture content at field capacity is used for the soil.
\end{abstract}

Keywords: Heat and mass transfer, soil, numerical analysis, finite volume method, heat pulse

\section{INTRODUCTION}

Global warming is currently causing serious issues around the world such as typhoons [1], more diseases [2] for humans, and habitat damages [3]. Consequently, many governments around the globe have devoted heavy efforts in reducing global warming which results from heavy consumption of energies (mostly fossil fuels) [3, 4]. Renewable energies have been encouraged to be used as they are more environmental friendly than the fossil fuels. A highly abundant and attractive renewable energy is the solar radiation from the Sun.

In order to store the thermal energy from solar radiation, thermal energy storages (TESs) are needed. A common and widely used TES form is the ground thermal energy storage (GTES). Storing at higher temperatures in the GTESs can better utilize the GTES. Consequently, it is better to store the solar heat in high-temperature (above $40^{\circ} \mathrm{C}$ ) ground because the heat can be readily retrieved for space heating without the use of a heat pump. A first-in-the-world example of successful application of using high temperature GTES is the Drake Landing Solar Community in Okotos, Alberta, Canada. The GTES can provide $90 \%$ space heating needs for the Community. The ground in Okotos contains mostly clay which has low moisture diffusivity, so the GTES in the Drake Landing Solar Community can store and retain most of the heat in the summer. However, not everywhere in the world has such type of soil. Therefore, understanding how heat and moisture transfer in various soil types at high temperatures is beneficial to the design of high-temperature GTES.

\section{GOVERNING EQUATIONS}

Modeling transport phenomena in the ground has been of great interests. The pioneers in modeling include Philip and de Vries [5] and Luikov [6]. Governing equations were developed based on the soil's hydraulic conductivity, temperature gradients, moisture potential, and volumetric moisture content. Heat conduction incorporating latent heat transfer by water vapor diffusion was considered and generalized with moisture and latent heat storage in vapor phase and sensible heat transfer by liquid migration in the soil.

Another early work was done by Demsey [7] who studied the coupled heat and moisture transfer and applied the finite difference method to numerically study the one-dimensional moisture in Lakeland fine sand (AASHO Classification A-3) under isothermal conditions (maximum $25^{\circ} \mathrm{C}$ ). Comparisons with laboratory experimental data showed good agreements between the numerical work and the lab data.

Rees et al. [8] and Janssen et al. [9] coupled heat and mass transfer equations to study how the moisture content affects the heat losses in underground structures. The researchers found that the coupled calculations give significantly higher heat losses than the calculations from simple heat and moisture transfer. In addition, the latent heat transfer by thermal vapor diffusion has a notable influence on the foundation heat loss.

Fully coupled heat and mass transfer equations can be formulated based on physical processes that occur in the soil can be described as follow [10]:

$$
\begin{gathered}
C_{\psi m} \frac{\partial \psi}{\partial t}+C_{T m} \frac{\partial T}{\partial t}=\nabla \cdot\left(D_{\psi m} \nabla \psi\right)+\nabla \cdot\left(D_{T m} \nabla T\right)+\frac{\partial K}{\partial z} \\
C_{\psi T} \frac{\partial \psi}{\partial t}+C_{T T} \frac{\partial T}{\partial t}=\nabla \cdot\left(D_{\psi T} \nabla \psi\right)+\nabla \cdot\left(k_{e f f} \nabla T\right)+C_{p w} \dot{m}_{w} \cdot \nabla T \\
\text { where } C_{\psi m}=C_{\psi l}+C_{\psi v}, C_{T m}=C_{T l}+C_{T v}, C_{\psi T}=\rho_{l} \cdot h_{f g} \cdot C_{\psi v}, \\
C_{T T}=C_{s o i l}+\rho_{l} \cdot h_{f g} \cdot C_{T v}, C_{\psi l}=\left(\frac{\partial \theta_{l}}{\partial \psi}\right)_{T}, C_{T l}=\left(\frac{\partial \theta_{l}}{\partial T}\right)_{\psi}, \\
D_{\psi m}=K+D_{\psi v}, D_{T m}=D_{T v}, D_{\psi T}=\rho_{l} \cdot h_{f g} \cdot D_{\psi v},
\end{gathered}
$$




$$
\begin{gathered}
D_{\psi v}=f\left(\theta_{l}\right) D_{v a} \frac{\rho_{v s}}{\rho_{l}} \frac{\varphi g}{R_{w} T}, \dot{m}_{w}=\rho_{l} u_{l}, \varphi=\exp \left(\frac{\psi g}{R_{w} T}\right), \\
C_{\psi v}=\frac{\rho_{v s} \varphi}{\rho_{l}}\left[\frac{\left(\eta-\theta_{l}\right) g}{R_{w} T}-\left(\frac{\partial \theta_{l}}{\partial \psi}\right)_{T}\right], \quad C_{T_{v}}=\frac{\rho_{v s} \varphi}{\rho_{l}}\left[\frac{\eta-\theta_{l}}{\rho_{v s}}\left(\frac{\partial \rho_{v s}}{\partial T}\right)-\left(\frac{\partial \theta_{l}}{\partial T}\right)_{\psi}\right], \\
D_{T v}=f\left(\theta_{l}\right) D_{v a} \varphi \frac{\rho_{v s}}{\rho_{l}}\left[\frac{1}{\rho_{v s}} \frac{\partial \rho_{v s}}{\partial T}-\frac{\psi g}{R_{w} T^{2}}+\frac{g}{R_{w} T}\left(\frac{\partial \psi}{\partial T}\right)_{\theta}\right] \frac{(\nabla T)_{p}}{\nabla T}, \\
K=K_{s a t} \frac{\left[1-|\alpha \psi|^{n-1}\left(1+|\alpha \psi|^{n}\right)^{-m}\right]^{2}}{\left(1+|\alpha \psi|^{n}\right)^{n / 2}}, \frac{(\nabla T)_{p}}{\nabla T}=\xi \cdot\left(\theta_{w}+\xi_{p} \theta_{p}+\sum_{i=1}^{n} \xi_{i} \theta_{i}\right)^{-1}
\end{gathered}
$$

and more definitions can be found in [10].

Eq. 1a is the moisture transfer equation in the soil and Eq. $1 b$ is the energy transfer equation in the soil. The terms on the left hand sides correspond to the stored mass and energy due to the temporal change in matric potential and temperature. The first two terms on right hand sides account for the mass transfer (Eq. 1a) and heat transfer (Eq. 1b) respectively due to moisture and temperature gradients. The last term in Eq. 1a represents the mass transfer by gravitational effects while that in Eq. $1 \mathrm{~b}$ is the sensible heat transfer by bulk liquid flow. The second term in square brackets of $D_{T v}$ is significant for $\psi<$ $10^{-4} \mathrm{~m}$ while the third term is needed for $\psi<-10^{-5} \mathrm{~m}$ [10].

As indicated by Deru [10], the last term on the right hand side (RHS) of Eq. $1 \mathrm{~b}$ is significant for only a short period after a large influx of moisture such as rainfall or irrigation. In the present experiment, there is no moisture addition into the soil during experimentation; therefore, the last term on the RHS of Eq. $1 \mathrm{~b}$ is ignored.

\section{EXPERIMENTAL SETUP}

The soil used is called Victoria soil (coded NB2 [11]) from Northern Victoria County in New Brunswick, Canada. It is a silt loam with solid density of $2540 \mathrm{~kg} / \mathrm{m}^{3}, 16.6 \%$ clay and $83.4 \%$ silt (by mass). The moist soil was prepared and packed carefully into a soil column.

In order to verify the governing equations (i.e., Eq. 1), a soil cell assembly is made as shown in Fig. 1. The heat pulse method is used to obtain soil temperature response due to a heat pulse, and a computer program developed by Knight $e t$ al. [11] is used to post-process the temperature response data in order to determine soil thermal properties and moisture content.

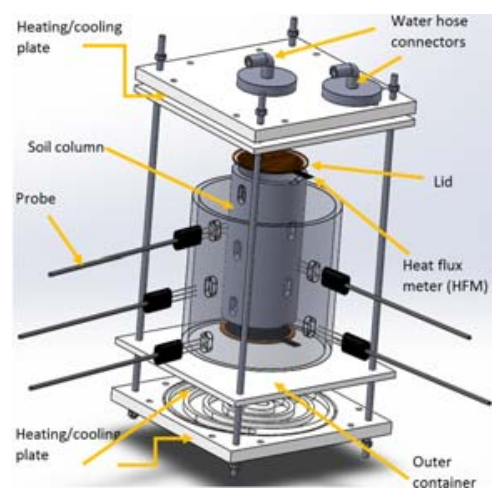

Figure 1. Soil cell assembly.
Fig. 2 shows a close-up view of a heat pulse probe. For ease of viewing the inner soil column in Fig. 1, the outer stainless-steel tube and lids are shown transparently. Water hose connectors are connected to thermally-controlled water baths (which provide the heating and cooling to the aluminum plates) through water hoses. The soil column is a stainlesssteel tube (63.5 $\mathrm{mm}$ ID, $76.2 \mathrm{~mm}$ OD, $147.9 \mathrm{~mm}$ length) that has five slots for inserting five heat pulse probes. The heating/cooling plates are made of aluminum. The soil cell assembly is connected to a data acquisition system that collects experimental data.

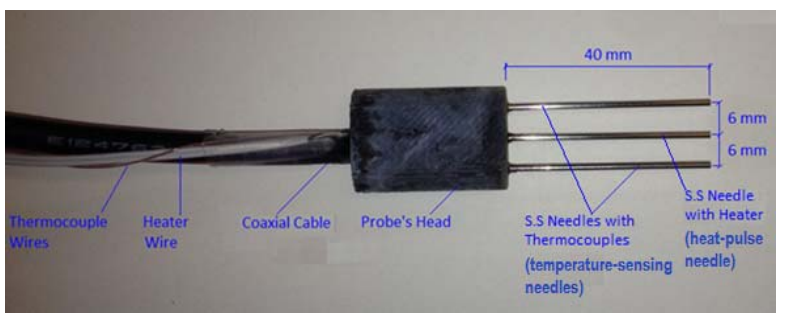

Figure 2. An in-house made heat pulse probe.

\section{NUMERICAL SOLUTION}

\section{A. One-dimensional Discretization Formulations - Finite Volume Method}

The one-dimensional finite volume formulations are developed according to the discretization schme shown in Fig. 3 with the following assumptions:

- The height of the soil column is $h$ (distance from node A to node B)

- There are $n$ control volumes (CVs) along $h$

- Each CV has length $\Delta z$ of $h / n$

- The distance from node A to node 1 is the same as that from $n$ to $\mathrm{B}$ and is equal to $\Delta z / 2$

- There are $n+2$ nodes

- The temperatures at nodes A and B are known at all times

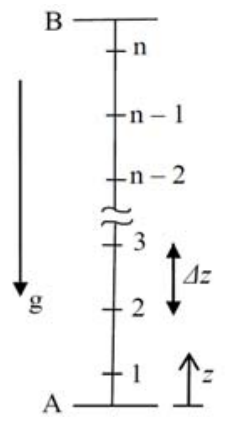

Figure 3. One-dimensional discretization scheme.

Discretizing Eq. 1 for nodes 2 to $n-1$ gives:

$$
\begin{aligned}
& a_{1} \psi_{P}+a_{2} T_{P}=a_{3} \psi_{N}+a_{4} T_{N}+a_{5} \psi_{S}+a_{6} T_{S}+G_{1} \\
& b_{1} \psi_{P}+b_{2} T_{P}=b_{3} \psi_{N}+b_{4} T_{N}+b_{5} \psi_{S}+b_{6} T_{S}+G_{2}
\end{aligned}
$$

where $a_{1}=C_{\psi m}+a_{3}+a_{5}, a_{2}=C_{T m}+a_{4}+a_{6}, b_{1}=C_{\psi T}+b_{3}+b_{5}$, $b_{2}=C_{T T}+b_{4}+b_{6}, \quad a_{3}=\frac{\beta \Delta t}{(\Delta z)^{2}}\left(D_{\psi m}\right)_{n}, a_{4}=\frac{\beta \Delta t}{(\Delta z)^{2}}\left(D_{T m}\right)_{n}, \quad \beta=0.5$ 


$$
\begin{gathered}
a_{5}=\frac{\beta \Delta t}{(\Delta z)^{2}}\left(D_{\psi m}\right)_{s} \quad a_{6}=\frac{\beta \Delta t}{(\Delta z)^{2}}\left(D_{T m}\right)_{s}, \quad b_{3}=\frac{\beta \Delta t}{(\Delta z)^{2}}\left(D_{\psi T}\right)_{n}, \\
b_{4}=\frac{\beta \Delta t}{(\Delta z)^{2}}\left(k_{e f f}\right)_{n}, \quad b_{5}=\frac{\beta \Delta t}{(\Delta z)^{2}}\left(D_{\psi T}\right)_{s}, \quad b_{6}=\frac{\beta \Delta t}{(\Delta z)^{2}}\left(k_{e f f}\right)_{s}, \\
G_{1}=\left\{C_{\psi m}-\frac{(1-\beta)}{\beta}\left[a_{3}^{o}+a_{5}^{o}\right]\right\} \psi_{P}^{o}+\left\{C_{T m}-\frac{(1-\beta)}{\beta}\left[a_{4}^{o}+a_{6}^{o}\right]\right\} T_{P}^{o} \\
+\frac{(1-\beta)}{\beta}\left\{a_{3}^{o} \psi_{N}^{o}+a_{5}^{o} \psi_{S}^{o}+a_{4}^{o} T_{N}^{o}+a_{6}^{o} T_{S}^{o}+\Delta z\left(K_{n}^{o}-K_{s}^{o}\right)\right\}+\frac{\beta \Delta t}{\Delta z}\left\{K_{n}-K_{s}\right\} \\
G_{2}=\left\{C_{\psi T}-\frac{(1-\beta)}{\beta}\left[b_{3}^{o}+b_{5}^{o}\right]\right\} \psi_{P}^{o}+\left\{C_{T T}-\frac{(1-\beta)}{\beta}\left[b_{4}^{o}+b_{6}^{o}\right]\right\} T_{P}^{o} \\
+\frac{(1-\beta)}{\beta}\left\{b_{3}^{o} \psi_{N}^{o}+b_{5}^{o} \psi_{S}^{o}+b_{4}^{o} T_{N}^{o}+b_{6}^{o} T_{S}^{o}\right\}
\end{gathered}
$$

where the superscript ${ }^{\circ}$ means the value at previous time step, $\mathrm{P}$ means the centroid of the current $\mathrm{CV}$ being considered, $\mathrm{N}$ means the north of the CV's centroid, $\mathrm{S}$ means the south of the CV's centroid.

The temperatures at nodes $\mathrm{A}$ and $\mathrm{B}\left(T_{A}\right.$ and $\left.T_{B}\right)$ are measured in the experiment and therefore they are used as prescribed boundary temperatures. The moisture balance at nodes $\mathrm{A}$ and $\mathrm{B}$, for impermeable surfaces due to the stainlesssteel lids, is [10]:

$$
0=-K \frac{\partial \Phi}{\partial n}-D_{\psi v} \frac{\partial \psi}{\partial n}-D_{T m} \frac{\partial T}{\partial n}
$$

where $\Phi=\psi+z$ with $z$ being positive upwards ( $z=0$ at node A) and $\partial / \partial n=\partial / \partial z$.

As a result of Eq. 4, the matric potential gradients at nodes $\mathrm{A}$ and $\mathrm{B}$ respectively are:

$$
\begin{gathered}
\left.\frac{\partial \psi}{\partial z}\right|_{A}=\frac{-1}{K+D_{\psi v}}\left(\left.D_{T m} \frac{\partial T}{\partial z}\right|_{z=A}+K\right) \\
\left.\frac{\partial \psi}{\partial z}\right|_{B}=\frac{-1}{K+D_{\psi v}}\left(\left.D_{T m} \frac{\partial T}{\partial z}\right|_{z=B}+K\right)
\end{gathered}
$$

Applying Eq. 5a, the discretized governing equations at node 1 are:

$$
\begin{aligned}
& a_{1} \psi_{1}+a_{2} T_{1}=a_{3} \psi_{2}+a_{4} T_{2}+a_{5} \psi_{A}+a_{6} T_{A}+G_{1} \\
& b_{1} \psi_{1}+b_{2} T_{1}=b_{3} \psi_{2}+b_{4} T_{2}+b_{5} \psi_{A}+b_{6} T_{A}+G_{2}
\end{aligned}
$$

where $a_{1}=C_{\psi m}+a_{3}+a_{5}, \quad a_{2}=C_{T m}+a_{4}+a_{6}, b_{1}=C_{\psi T}+b_{3}+b_{5}$, $b_{2}=C_{T T}+b_{4}+b_{6}, \quad a_{3}=\frac{\beta \Delta t}{(\Delta z)^{2}}\left(D_{\psi m}\right)_{2}, \quad a_{4}=\frac{\beta \Delta t}{(\Delta z)^{2}}\left(D_{T m}\right)_{2}, \quad a_{5}=0$,

$$
\begin{gathered}
a_{6}=\frac{2 \beta \Delta t}{(\Delta z)^{2}}\left[\left(D_{T m}\right)_{1}+\left(\Lambda_{a}\right)_{1}\right], \quad b_{3}=\frac{\beta \Delta t}{(\Delta z)^{2}}\left(D_{\psi T}\right)_{2}, b_{4}=\frac{\beta \Delta t}{(\Delta z)^{2}}\left(k_{e f f}\right)_{2}, \\
b_{5}=0, \quad b_{6}=\frac{2 \beta \Delta t}{(\Delta z)^{2}}\left[\left(k_{e f f}\right)_{1}+\left(\Lambda_{b}\right)_{1}\right], \quad \Lambda_{a}=\left(\frac{-D_{T m} \cdot D_{\psi m}}{K+D_{\psi v}}\right)_{1}, \\
\Lambda_{b}=\left(\frac{-D_{T m} \cdot D_{\psi T}}{K+D_{\psi v}}\right)_{1}, K_{1} \text { means } K \text { at node } 1, \text { and }
\end{gathered}
$$

$\left(D_{x x}\right)_{1}$ and $\left(k_{e f f}\right)_{1}$ mean $D_{x x}$ and $k_{\text {eff }}$ of CV 1 respectively

$$
\begin{aligned}
G_{1}= & \left\{C_{\psi m}-\frac{(1-\beta)}{\beta} a_{3}^{o}\right\} \psi_{1}^{o}+\left\{C_{T m}-\frac{(1-\beta)}{\beta}\left[a_{4}^{o}+a_{6}^{o}\right]\right\} T_{1}^{o} \\
& +\frac{\beta \Delta t}{\Delta z}\left\{K_{2}-K_{1}+\left(\frac{\Lambda_{a} K}{D_{T m}}\right)\right\} \\
& +\frac{(1-\beta)}{\beta}\left\{a_{3}^{o} \psi_{2}^{o}+a_{4}^{o} T_{2}^{o}+a_{6}^{o} T_{A}^{o}+\frac{\beta \Delta t}{\Delta z}\left(K_{2}^{o}-K_{1}^{o}+\left(\frac{\Lambda_{b} K}{D_{T m}}\right)_{1}^{o}\right)\right\} \\
G_{2}= & \left\{C_{\psi T}-\frac{(1-\beta)}{\beta} b_{3}^{o}\right\} \psi_{1}^{o}+\left\{C_{T T}-\frac{(1-\beta)}{\beta}\left[b_{4}^{o}+b_{6}^{o}\right]\right\}_{1}^{o} . \\
& +\frac{(1-\beta)}{\beta}\left\{b_{3}^{o} \psi_{2}^{o}+b_{4}^{o} T_{2}^{o}+b_{6}^{o} T_{A}^{o}\right\}
\end{aligned}
$$

Applying Eq. 5b, the discretized governing equations at node $n$ are:

$$
\begin{aligned}
& a_{1} \psi_{n}+a_{2} T_{n}=a_{3} \psi_{B}+a_{4} T_{B}+a_{5} \psi_{n-1}+a_{6} T_{n-1}+G_{1} \\
& b_{1} \psi_{n}+b_{2} T_{n}=b_{3} \psi_{B}+b_{4} T_{B}+b_{5} \psi_{n-1}+b_{6} T_{n-1}+G_{2}
\end{aligned}
$$

where $a_{1}=C_{\psi m}+a_{3}+a_{5}, a_{2}=C_{T m}+a_{4}+a_{6}, b_{1}=C_{\psi T}+b_{3}+b_{5}$, $b_{2}=C_{T T}+b_{4}+b_{6} \quad, \quad a_{3}=0 \quad, \quad a_{4}=\frac{\beta \Delta t}{(\Delta z)^{2}}\left(D_{T m}\right)_{n-1}$, $a_{5}=\frac{\beta \Delta t}{(\Delta z)^{2}}\left(D_{\psi m}\right)_{n-1} \quad, \quad a_{6}=\frac{2 \beta \Delta t}{(\Delta z)^{2}}\left[\left(D_{T m}\right)_{n}+\left(\Lambda_{c}\right)_{n}\right], \quad b_{3}=0$, $b_{4}=\frac{\beta \Delta t}{(\Delta z)^{2}}\left(k_{e f f}\right)_{n-1}, \quad b_{5}=\frac{\beta \Delta t}{(\Delta z)^{2}}\left(D_{\psi T}\right)_{n-1}, \quad b_{6}=\frac{2 \beta \Delta t}{(\Delta z)^{2}}\left[\left(k_{e f f}\right)_{n}+\left(\Lambda_{d}\right)_{n}\right]$,

$$
\begin{aligned}
G_{1}= & \left\{C_{\psi m}-\frac{(1-\beta)}{\beta} a_{5}^{o}\right\} \psi_{n}^{o}+\left\{C_{T m}-\frac{(1-\beta)}{\beta}\left[a_{5}^{o}+a_{6}^{o}\right]\right\} T_{n}^{o} \\
& +\frac{\beta \Delta t}{\Delta z}\left\{K_{n}-K_{n-1}+\left(\frac{\Lambda_{c} K}{D_{T m}}\right){ }_{n}\right\} \\
& +\frac{(1-\beta)}{\beta}\left\{a_{5}^{o} \psi_{n-1}^{o}+a_{4}^{o} T_{n-1}^{o}+a_{6}^{o} T_{B}^{o}+\frac{\beta \Delta t}{\Delta z}\left(K_{n}^{o}-K_{n-1}^{o}+\left(\frac{\Lambda_{c} K}{D_{T m}}\right)_{n}^{o}\right)\right\}
\end{aligned}
$$

$$
\begin{array}{rlr}
G_{2}= & \left\{C_{\psi T}-\frac{(1-\beta)}{\beta} b_{5}^{o}\right\} \psi_{n}^{o}+\left\{C_{T T}-\frac{(1-\beta) \Delta t}{(\Delta z)^{2}}\left[b_{4}^{o}+b_{6}^{o}\right]\right\} T_{n}^{o}, \\
& +\frac{(1-\beta)}{\beta}\left\{b_{5}^{o} \psi_{n-1}^{o}+b_{4}^{o} T_{n-1}^{o}+b_{6}^{o} T_{B}^{o}\right\} \\
\Lambda_{c}= & \left(\frac{-D_{T m} \cdot D_{\psi m}}{K+D_{\psi v}}\right)_{n}, & \Lambda_{d}=\left(\frac{-D_{T m} \cdot D_{\psi T}}{K+D_{\psi v}}\right)_{n},
\end{array}
$$

where $K_{n}$ means $K$ at node $n$, and $\left(D_{x x}\right)_{n}$ and $\left(k_{\text {eff }}\right)_{n}$ mean $D_{x x}$ and $k_{\text {eff }}$ of CV $n$ respectively.

The initial conditions are as follows:

1. The temperatures at all nodes are at room temperature $\left(\sim 23^{\circ} \mathrm{C}\right)$

2. The relative humidity $(\varphi)$ of dry soil is the same as that of the lab room $(\sim 23 \%)$

3. The initial moisture content in wet soil can be used to calculate the initial matric potential using van Genuchten's method [12].

\section{B. Solution Method}

Identify applicable sponsor/s here. (sponsors) 
For faster convergence, the partial elimination algorithm (PEA) [13] is applied to Eqs. 3, 6, and 7 as follow:

$$
\begin{gathered}
a_{1} \psi_{P}+a_{2} T_{P}=\sum a_{F}^{\psi} \psi_{F}+G_{3} \\
b_{1} \psi_{P}+b_{2} T_{P}=\sum a_{F}^{T} T_{F}+G_{4}
\end{gathered}
$$

where $\sum a_{F}^{\psi} \psi_{F}=a_{3} \psi_{N}+a_{5} \psi_{S}, \quad G_{3}=G_{1}+a_{4} T_{N}+a_{6} T_{S}$

$$
\sum a_{F}^{T} T_{F}=b_{3} T_{N}+b_{5} T_{S}, \quad G_{4}=G_{2}+b_{4} \psi_{N}+b_{6} \psi_{S}
$$

The expressions for $a_{\mathrm{i}}$ and $b_{\mathrm{i}}, G_{1}$ and $G_{2}$ can be derived from Eqs. 3, 6, and 7 for the nodes.

Multiplying Eq. 8a with $b_{2}$ and Eq. 8b with $a_{2}$ and isolating $\psi_{P}$ :

$$
a_{P}^{\psi} \psi_{P}=\sum a_{F}^{\psi} \psi_{F}+B_{P}^{\psi}
$$

where $a_{P}^{\psi}=\frac{a_{1} b_{2}-a_{2} b_{1}}{b_{2}}$ and $B_{P}^{\psi}=G_{3}-\frac{a_{2}}{b_{2}}\left(\sum a_{F}^{T} T_{F}+G_{4}\right)$

Similarly, multiplying Eq. 8a with $b_{1}$ and Eq. $8 \mathrm{~b}$ with $a_{1}$ and isolating $T_{P}$ :

$$
a_{P}^{T} T_{P}=\sum b_{F}^{T} T_{F}+B_{P}^{T}
$$

where $a_{P}^{T}=\frac{a_{1} b_{2}-a_{2} b_{1}}{a_{1}}$ and $B_{P}^{T}=G_{4}-\frac{b_{1}}{a_{1}}\left(\sum a_{F}^{\psi} \psi_{F}+G_{3}\right)$

Since the convection and diffusion coefficients are highly non-linear, an iterative approach is adopted from Moukalled and Saleh [13]:

1. Assume reasonable values for $\psi\left(\psi_{\text {guess }}\right)$ and $T\left(T_{\text {guess }}\right)$

2. Calculate the physical properties of soil using $\psi_{\text {guess }}$ and $T_{\text {guess }}$

3. Calculate the coefficients in Eqs. 3a, 6a, and 7a using $\psi_{\text {guess }}$ and $T_{\text {guess }}$

4. Obtain the coefficients in Eq. 9 using $\psi_{\text {guess }}$ and $T_{\text {guess }}$

5. Using tridiagonal matrix algorithm (TDMA), solve for nodal $\psi$ values $\left(\psi^{i}\right)$ where $i$ means current iteration and

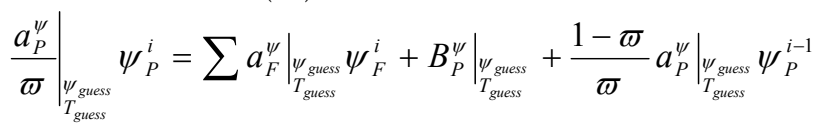

6. Calculate the coefficients in Eqs. $3 b, 6 b$, and $7 b$ using $\psi^{i}$ and $T_{\text {guess }}$

7. Calculate the coefficients in Eq. 10 using $\psi^{i}$ and $T_{\text {guess }}$

8. Using TDMA, solve for nodal $T$ values $\left(T^{i}\right)$ where $i$ means current iteration and

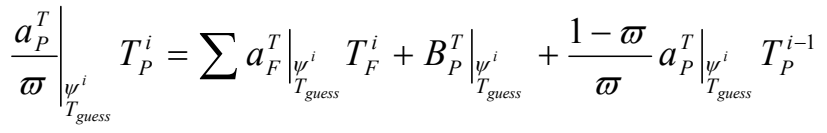

9. Compare $\psi^{i}$ and $T^{i}$ with the corresponding $\psi_{\text {guess }}$ and $T_{\text {guess }}$ as:

$$
\varepsilon_{\psi}=\frac{\psi^{i}-\psi_{\text {guess }}}{\psi_{\text {guess }}} \quad \text { and } \quad \varepsilon_{T}=\frac{T^{i}-T_{\text {guess }}}{T_{\text {guess }}}
$$

10. If $\varepsilon_{\psi}<0.001$ and $\varepsilon_{T}<0.001$, proceed to the next time step. Otherwise, repeat steps $1-9$ with $\psi_{\text {guess }}=\psi^{i}$ and $T_{\text {guess }}=T^{i}$ and $i$ in steps $5-9$ becomes $i+1$ and $i-1$ becomes $i$

\section{Matlab Code Validation}

The computer code is programmed in Matlab. First, it is necessary to perform a grid sensitivity study for deciding the optimum amount of nodes for subsequent numerical study. Figure 4 shows a graph of the percentage root-mean-square differences of temperature $(T)$ and moisture content $(\theta)$ vs. number of nodes at time of 30 minutes with a simulation timestep of $1 s$ in the case of heating top of the soil column to $90^{\circ} \mathrm{C}$ and cooling the bottom to $10^{\circ} \mathrm{C}$. The percentage root-meansquare difference (\% RMS Difference) is defined as:

$$
\frac{\% \text { RMS Difference }}{100 \%}=\sqrt{\sum_{i=1}^{n_{\text {ferer noldes }}}\left(\frac{\Xi_{2+3(i-1) \text {,more nodes }}-\Xi_{i, \text { fwer nodes }}}{n_{\text {fever nodes }}} \Xi_{i, \text { fewer nodes }}\right.}
$$

where $\Xi_{i}$ represents $T_{i}$ or $\theta_{i}$ at node $i$ and $n_{\text {fewer nodes }}$ is the total number of finite volumes or nodes in the case of fewer nodes. The successive increase of nodes is by tripling, i.e. more nodes $=3 \times($ fewer nodes $)$, so that the same height points between the case of fewer nodes and the case of more nodes can be compared directly, i.e., node number of $2+3 \times(i-1)$ in the case of more nodes has the same position as node number $i$ in the case of fewer nodes.

From Fig. 4, it can be seen that, as the number of nodes increases, the successive percentage RMS differences of $T$ and $\theta$ become smaller, which means that the values of $T$ and $\theta$ are converging toward an infinite-node solution. Due to limited computing power, memory and time constraint, it is decided to use 4437 finite volumes for the rest of the numerical study. For this number of finite volumes, the percentage RMS differences of $T$ and $\theta$ between 4000 and 6000 nodes are less than $1.1 \%$, and the size of each finite volume is about $33.3 \mu \mathrm{m}$.

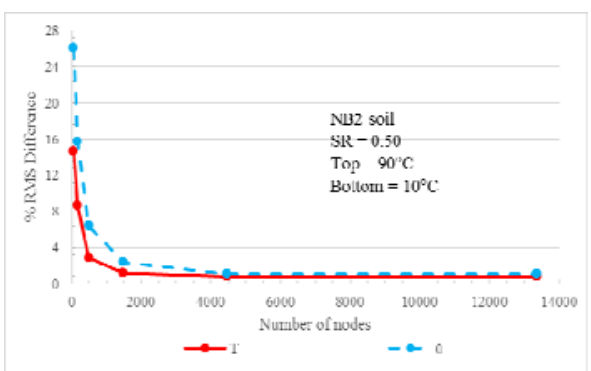

Figure 4. \% RMS differences of $T$ and $\theta v$ s. number of nodes.

The next step is to validate the Matlab code by simulating two cases, namely: only heat transfer and only moisture transfer. For the first case, a soil column (assumed to be semiinfinite) of height of $2 \mathrm{~m}$, density of $2,000 \mathrm{~kg} / \mathrm{m}^{3}$, thermal conductivity of $2.51 \mathrm{~W} / \mathrm{m} \cdot \mathrm{K}$, heat capacity of $837.2 \mathrm{~J} / \mathrm{kg} \cdot \mathrm{K}$, porosity of 0.50 , and initial uniform temperature $293 \mathrm{~K}$ are used. The top surface temperature of the soil is suddenly 
raised to $310 \mathrm{~K}$ (or $37^{\circ} \mathrm{C}$ ) at time $t=0$ and held constant. The numerical simulation is used to predict the temperature distribution in the soil after 1, 4, 9, 16, and 25 hours. The simulation time-step used is $1 \mathrm{~s}$. The results obtained are compared to the analytical solution of transient pure conduction in a semi-infinite wall [A64], assuming the heat flows in the vertical direction only. The derivation of the analytical solution assumes constant thermal properties, so Case 1 is limited to small temperature difference of $\Delta T=310$ $-293=17 \mathrm{~K}$ to reduce the effect of temperature on the thermal properties.

Fig. 5 shows the temperature distributions of the semiinfinite soil column at different times from the numerical model (i.e., Eq. 1) and the analytical solution. As shown in Fig. 5, the numerical solution from the Matlab code matches with the analytical solution.

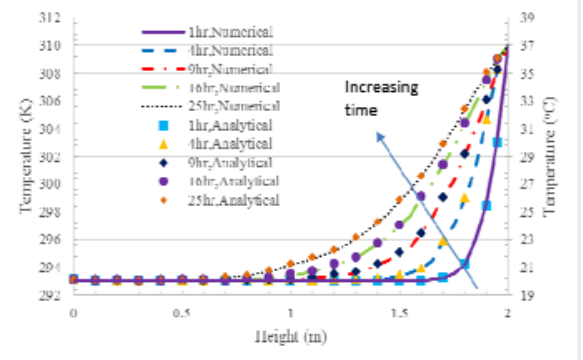

Figure 5. Temperature distributions of semi-infinite soil column at different times from numerical and analytical solutions.

For the second case, a column $(0.4 \mathrm{~m}$ high, assumed semiinfinite) of Yolo light clay soil is used to study the moisture behavior in the soil under isothermal condition at the room temperature. The soil initially is not fully saturated and subjected to an inflow of liquid water at the top surface such that the matric potential at the top surface (i.e., $z=40 \mathrm{~cm}$ ) is always constant at 0 or $-25 \mathrm{~cm}$. The matric potential at the bottom surface (i.e., $z=0 \mathrm{~cm}$ ) is always held constant at -600 $\mathrm{cm}$. Neglecting the vapor and thermal effects, the governing equation in one dimension can be written as [15]:

$$
\left(\frac{\partial \theta}{\partial \psi}\right) \frac{\partial \psi}{\partial t}=\frac{\partial}{\partial z}\left(K \frac{\partial \psi}{\partial z}\right)+\frac{\partial K}{\partial z}
$$

The initial and boundary conditions are: $\psi(0 s, z)=-6 m$, $\psi(t, 0.40 \mathrm{~m})=0 \mathrm{~m}$ or $-0.25 \mathrm{~m}$, and $\psi(t, 0 \mathrm{~m})=-6 \mathrm{~m}$.

Fig. 6 shows the numerical and analytical (from Philip [15]) solutions of moisture distributions at four different times of $10^{3} s(16.7 \mathrm{mins}), 10^{4} s(2.8 \mathrm{hrs}), 4 \times 10^{4} \mathrm{~s}(11.1 \mathrm{hrs})$ and $10^{5}$ $s(27.8 \mathrm{hrs})$ after moisture is first added at the top surface of the soil. As shown in the figure, when the top surface is fully saturated (i.e., $\psi$ is zero) or has a pool of water (i.e., $\psi$ is positive), more moisture can infiltrate into deeper places of the soil column. In addition, the water slowly infiltrates through the soil as clay is a fine soil which has low moisture permeability. Again, the numerical solution from the Matlab code matches very well with the analytical solution. After the two validations of the code, it is ready to simulate an actual experimental case and compare the results.
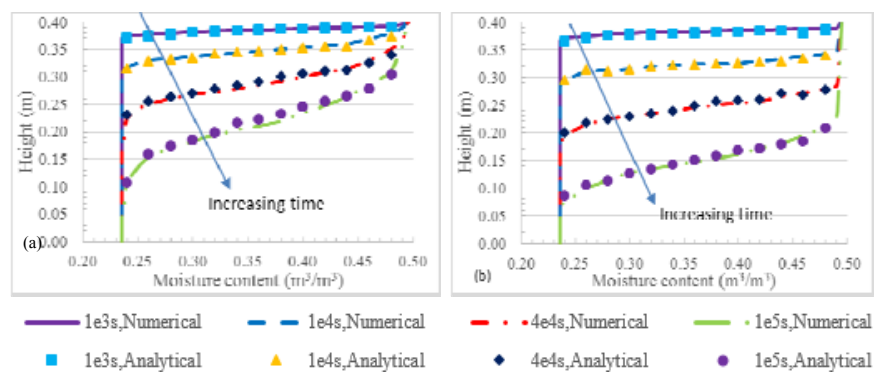

Figure 6. Moisture distributions in Yolo light clay soil column from numerical and analytical solutions for $(a) \psi(t, 40 \mathrm{~cm})=$ $0 \mathrm{~cm}$ and $(b) \psi(t, 40 \mathrm{~cm})=-25 \mathrm{~cm}$.

\section{VERIFICATION OF EQ. 1}

A comparison between numerical and experimental results is made for a case of vertical soil column with the top of the soil cell heated to $90^{\circ} \mathrm{C}$ and the bottom cooled to $10^{\circ} \mathrm{C}$. The initial saturation ratio (SR) of the soil is 0.50 throughout the soil column. Each heat pulse probe can measure two positions of soil temperatures and moisture contents. Therefore, there are a total of ten positions from top to bottom of the soil column for the five probes; they are named N1 to N10, respectively. Fig. 7 shows the \% Errors (in terms of $T$ and $\theta$ ) for all ten positions over the experiment period of 18 hours. The \% Error is defined as follows:

$$
\% \text { Error }=100 \% \times \frac{(\operatorname{Tor} \theta)_{E q, 1}-(T \text { or } \theta)_{\text {experiment }}}{(T \text { or } \theta)_{\text {experiment }}}
$$

From the figure, it can be seen that the theoretical model (Eq. 1) over-predicts the moisture contents by as much as $6.2 \%$ at $\mathrm{N} 1$ but under-predicts the temperatures by as much as $2.1 \%$ at N1. When the moisture content is over-predicted, the temperature becomes lower as there is more moisture around the region, resulting in higher thermal capacitance of the soil. The top near N1 is the most critical region because it experiences high temperatures and thermal gradients

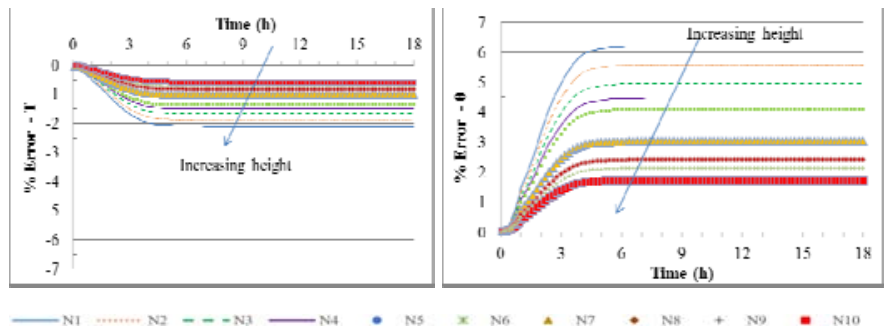

Figure 7. Percentage error of $T$ and $\theta$ (from $E q$. 1) for NB2 soil $(S R \approx 0.50)$ and vertically heated from top.

\section{CONCLUSION}

The theoretical governing equations of fully coupled heat and mass transfer in soils by Deru [10] was used to study how the moisture and thermal responses behaved in a soil column containing a silt loam (NB2 soil) with initial moisture at field capacity, i.e. a saturation ratio of 0.5 , and temperature settings of $90^{\circ} \mathrm{C}$ and $10^{\circ} \mathrm{C}$ at top and bottom plates. The onedimensional discretization formulations by the finite volume 
method were developed to numerically solve the governing equations. The numerical analysis was programmed in Matlab and verified to agree well with the existing literature. Running the Matlab code, the results showed good comparisons with the experimental results. The highest percent error appeared to be $6.2 \%$. This is an encouraging preliminary result. Further experimental and numerical studies with different soils, temperature settings and initial moisture contents will be conducted to fully understand the coupled heat and moisture transfer in soils for high-temperature GTES.

\section{NOMENCLATURE}

$C$
$C_{p}$
$C_{T v}, C_{T m}$
$C_{\psi T}, C_{T T}$
$C_{\psi v}, C_{\psi m}$
$D_{v a}$
$D_{T}$
$D_{\theta}$
$D_{T v}, D_{T m}$
$D_{\psi v}, D_{\psi m}$
$D_{\psi T}$
$f(), f$
$g$
$h_{f g}$
$K$
$k$
$\dot{m}$
$P$
$P_{v}$
$r$
$R_{w}$
$S$
$t$
$u$
$T$
$z$

Volumetric heat capacity $\left(\mathrm{J} / \mathrm{m}^{3} \cdot \mathrm{K}\right)$

Specific heat capacity $(\mathrm{J} / \mathrm{kg} \cdot \mathrm{K})$

Thermal vapor and total moisture capacitances $\left(K^{-1}\right)$

Matric $\left(\mathrm{J} / \mathrm{m}^{4}\right)$ and thermal $\left(\mathrm{J} / \mathrm{m}^{3} \cdot \mathrm{K}\right)$ volumetric heat capacitances

Matric vapor and total moisture capacitance terms $\left(\mathrm{m}^{-1}\right)$

Molecular diffusivity of water vapor in air $\left(\mathrm{m}^{2} / \mathrm{s}\right)$

Thermal diffusivity $\left(\mathrm{m}^{2} / \mathrm{s}\right)$

Isothermal moisture diffusivity $\left(\mathrm{m}^{2} / \mathrm{s}\right)$

Thermal vapor and total moisture diffusivities $\left(\mathrm{m}^{2} / \mathrm{s} \cdot \mathrm{K}\right)$

Matric vapor and total moisture diffusivities $\left(\mathrm{m}^{2} / \mathrm{s}\right)$

Matric potential heat diffusivity $\left(\mathrm{W} / \mathrm{m}^{2}\right)$

Correction and interpolation factors

Gravitational acceleration $\left(=9.804 \mathrm{~m} / \mathrm{s}^{2}\right)$

Latent heat of vaporization $(\mathrm{J} / \mathrm{kg})$

Hydraulic conductivity of soil $(\mathrm{m} / \mathrm{s})$

Thermal conductivity $(\mathrm{W} / \mathrm{m} \cdot \mathrm{K})$

Mass flux $\left(\mathrm{kg} / \mathrm{m}^{2} \cdot \mathrm{s}\right)$

Total pressure in pore spaces $(\mathrm{Pa})$

Partial vapor pressure in pore spaces $(\mathrm{Pa})$

Radius $(m)$

Specific gas constant for water vapor $(=461.5 \mathrm{~J} / \mathrm{kg} \cdot \mathrm{K})$

Surface area $\left(m^{2}\right)$

Time $(s)$

Bulk velocity $(\mathrm{m} / \mathrm{s})$

Temperature $\left(K\right.$ or $\left.{ }^{\circ} \mathrm{C}\right)$

Vertical distance $(m)$

\section{Greek symbols}

$\nabla$
$\varepsilon$
$\eta$
$\kappa$
$\mu$
$\varpi$
$\psi$
$\Phi$
$\rho$
$\sigma_{w a}$
$\tau$
$\theta$
$\Theta$
$\varphi$
$\xi$
$\Xi$

Del operator $\left(m^{-1}\right)$

Convergence criteria

Soil porosity ( $\mathrm{m}^{3}$ of pore space per $\mathrm{m}^{3}$ of soil)

Permeability of soil $\left(\mathrm{m}^{2}\right)$

Dynamic viscosity $(\mathrm{kg} / \mathrm{m} \cdot \mathrm{s})$

Relaxation factor of iteration

Matric liquid (capillary) potential (pressure head) $(\mathrm{m})$

Total soil matric potential for liquid flow $(m)$

Density $\left(\mathrm{kg} / \mathrm{m}^{3}\right)$

Surface tension of water in air $(\mathrm{N} / \mathrm{m})$

Empirical constant used in hydraulic conductivity equation

Volumetric moisture content/fraction $\left(\mathrm{m}^{3}\right.$ of water per $m^{3}$ of soil)

Degree of saturation

Relative humidity

Temperature gradient ratio $\left(=(\nabla T)_{p} /(\nabla T)\right)$

Dummy variable that represents another/other variable(s)

\section{Subscripts}

$a$

$c$
$C V$
$e f f$
$l$
$p$
$r e f$
$s$
$s a t$
$s v$
$T$
$t o t$
$\psi$
$v$
$w$

Pertaining to control volume

Effective

Liquid

Pore

Reference

Solid

Saturation

Saturated vapor

Pertaining to thermal conditions

Total

Pertaining to moisture conditions

Vapor

Water

Superscripts

T

i

Transpose

Current iteration

\section{REFERENCES}

[1] I.-I. Lin, I.F. Pun, C.-C. Lien; "Category-6 Super Typhoon Haiyan in Global Warming Hiatus: Contribution from Subsurface Ocean Warming”; AGU Geophysical Research Letters, pp. 8547 - 8553; 2014.

[2] International Federation of Red Cross and Red Crescent Societies, World Disaster Report, [Ch. 2]; IFRC; 2004.

[3] The Earth Project, Are Fossil Fuels Really Bad for the Environment?, http://theearthproject.com/fossil-fuels-bad-environment/, retrieved Feb. 12, 2018 .

[4] Richard Matthews, How to End our Fossil Fuel Addiction by 2050?, http://www.thegreenmarketoracle.com/2015/03/infographic-how-to-endfossil-fuels-by.html, The Green Market Oracle, retrieved Fen. 12, 2018.

[5] J. R. Philip, D. A. de Vries, "Moisture Movement in Porous Materials under Temperature Gradients", American Geophysical Union Transaction, Vol. 38 (2), pp. 222 - 232, 1957.

[6] A. V. Luikov, Heat and Mass Transfer in Capillary-Porous Bodies, Advances in Heat Transfer, edited by T. F. Irvine Jr. and J. P. Hartnett, pp. 123 - 184, 1964.

[7] B. J. Demsey, "A Mathematical Model for Predicting Coupled Heat and Water Movement in Unsaturated Soil", International Journal for Numerical and Analytical Methods in Geomechanics, 2, pp. 19-34, 1978.

[8] S. W. Rees, Z. Zhou, H. R. Thomas, "The Influence of Soil Moisture Content Variations on Heat Losses from Earth-Contact Structures: An Initial Assessment”, Building and Environment, 36, pp. 157-165, 2001.

[9] H. Janssen, J. Carmeliet, H. Hens, "The Influence of Soil Moisture in the Unsaturated Zone on the Heat Loss from Buildings via the Ground", Journal of Thermal Envelope \& Building Science, 25(4), pp. 275-298, 2002.

[10] M. Deru, A Model for Ground-Coupled Heat and Moisture Transfer from Buildings, Technical report (NREL/TP-550-33954, Contract No. DE-AC36-99-GO10337), National Renewable Energy Laboratory, 1617 Cole Boulevard, Golden, Colorado 80401-3393, USA, 2003.

[11] J. H. Knight, G. J. Kluitenberg, T. Kamai, J. W. Hopman, "Semianalytical Solution for Dual-Probe Heat-Pulse Applications that Accounts for Probe Radius and Heat Capacity", Vadose Zone J., Vol. 11 , Issue 2, 2012.

[12] M. T. van Genuchten, "A Close-Form Equation for Predicting the Hydraulic Conductivity of Unsaturated Soils", Soil Science Society of America Journal Vol. 44, pp. 892 - 898, 1980.

[13] F. Moukalled, S. Saleh, "Heat and Mass Transfer in Moist Soil, Part I. Formulation and Testing", Numerical Heat Transfer, Part B, Vol. 49, pp. 467-486, 2006

[14] F. P. Incropera, D. P. DeWitt, Fundamentals of Heat and Mass Transsfer, Wiley, New York, 2002.

[15] J. R. Philip, "The Theory of Infiltration: 1. The Infiltration Equation and its Solution", Soil Science, Vol. 83, pp. 435 - 448; 1957. 